\title{
Appendix F: Project Leadership
}

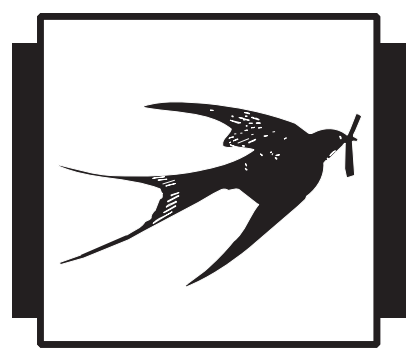

\section{F.1. Tool Sheet: Project Leader Role}

\section{What}

This tool sheet describes the project leader role seen as personal tasks and as personal behavior.

Use - Where and When

The project leader role is relevant in all project phases and should be adapted to the project type and conditions.

\section{Method}

\section{General Role Descriptions}

Mintzberg (1973) presented a general description of a leader's role and tasks that is also relevant for a project manager - formulated as ten roles of a leader. In addition to the roles, is it important to note that many project managers participate as technical leaders in some of the technical project work. The project manager should use the roles in view of her/his own situation. 


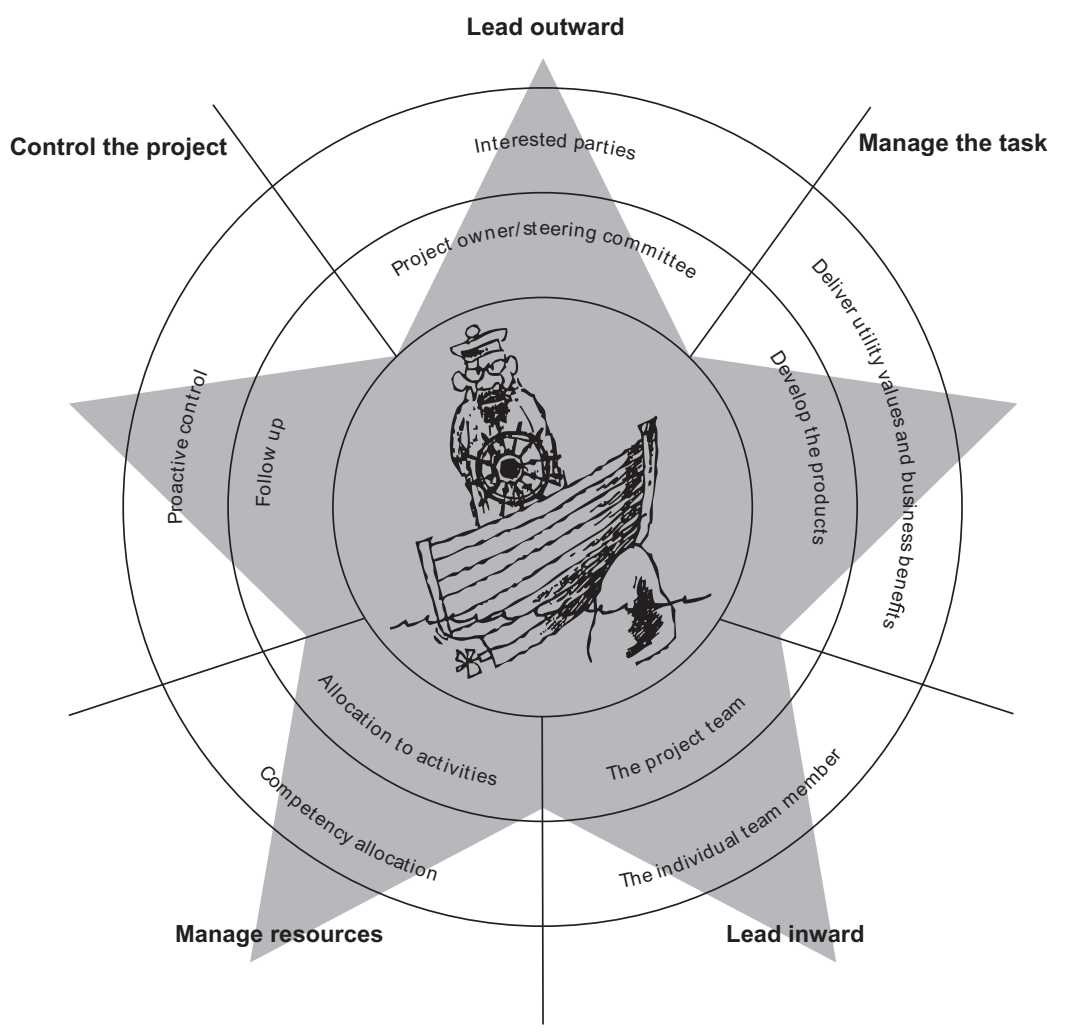

Figure F1. Project Leader's Five Management Areas.

Inspired by Mintzberg and developing the five management areas in Figure F1, we have formulated our version of the general roles of a project leader/manager - see Figure F2. It is a checklist for prioritizing own effort and for analyzing the personal effort.

\section{Issues to Consider When Selecting a Project Leader}

The project leader/manager may be recruited by evaluating qualifications (knowledge and experience) in the management areas in Figure F1:

- The user area - Insight into user's/customer's world, insight into disciplines and technology, degree of customer orientation. 


\begin{tabular}{|c|c|}
\hline \multicolumn{2}{|l|}{ Manage the task } \\
\hline Task manager & $\begin{array}{l}\text { Search for and identify opportunities. Take initiative. Define goals. } \\
\text { Delimit and choose. Evaluate results. Ensure coherence and results. }\end{array}$ \\
\hline \multicolumn{2}{|l|}{ Lead inward } \\
\hline Leader & $\begin{array}{l}\text { Motivate and engage team members. Create work milieu. Allocate and } \\
\text { release people. Ensure cooperation. }\end{array}$ \\
\hline Information distributor & $\begin{array}{l}\text { Pass on information to team members. Arrange internal } \\
\text { communication. Delegate activities and ensure task information. }\end{array}$ \\
\hline \multicolumn{2}{|l|}{ Lead outward } \\
\hline Figurehead & $\begin{array}{l}\text { Offical representative for the project and seen as the person with } \\
\text { status and authority. }\end{array}$ \\
\hline Connecting link & $\begin{array}{l}\text { Create and use contact network outside of the project team. Arrange } \\
\text { communication about project circumstances and conditions. }\end{array}$ \\
\hline Spokesman & $\begin{array}{l}\text { Pass on information about the project, plans, and results etc. to the } \\
\text { interested parties. Information to steering committee and project } \\
\text { responsible manager/Owner a.o. Public relations and missionary for } \\
\text { the project. }\end{array}$ \\
\hline Negotiator & $\begin{array}{l}\text { Participate in important negotiations with interested parties as } \\
\text { leader, spokesman, and support to project responsible manager. }\end{array}$ \\
\hline \multicolumn{2}{|l|}{ Project control } \\
\hline Activity manager & $\begin{array}{l}\text { Prepare and distribute plans. Arrange distribution of responsibilities. } \\
\text { Coordinate. Follow up and ensure progress. }\end{array}$ \\
\hline Crisis manager & Decide/act in critical situations and conflicts. \\
\hline Monitor & $\begin{array}{l}\text { Search for relevant information inside and outside. Use information to } \\
\text { explore opportunities and problems and to understand content and } \\
\text { conditions. Transform the information to ideas, action, and talk. }\end{array}$ \\
\hline \multicolumn{2}{|l|}{ Manage resources } \\
\hline Resource allocator & $\begin{array}{l}\text { Plan resource needs, identify competencies, arrange allocation of all } \\
\text { kinds of resources. }\end{array}$ \\
\hline
\end{tabular}

Figure F2. The Project Leader's Roles.

- The product technology area - Plan and manage product development and implementation, create and manage technical communication, judgment related to problems, and choice of solutions and quality.

- The change area - Arrange the approach to and manage the change process. Communicate with interested parties.

- The political area - Understand conflicts of interest and establish interaction between interested parties. Ability to maneuver in political environment. 
- The personal area outwards - Create understanding and acceptance of the project and of solutions.

- The personal area inwards - Project team and participants, natural leadership competency and authority. Ability to establish teamwork, to coordinate and to create good working conditions.

- The personal area inwards - The individual team member, natural leadership competency and authority, motivation, good working conditions, and performance development. Ability to lead specialists.

- The administrative and economy area - Planning and control.

- The resource area - Identify the need for competencies and effort and ability to provide them.

There may be different role profiles - predominantly 'inwards' leader or 'outwards' leader or 'technical content' leader. This picture may be related to the project processes and their importance and challenges. It is useful to pay attention to the ability to manage the system/product process versus the anchoring/change process.

Figure F3 shows a checklist with requirements for the project leader. The list may be used as basis for a specific list, aimed at an actual project leader job. Select relevant abilities from the list. It is probably not complete, but may direct the requirements to clusters. Use also a two to four-step scale to mark the importance of requirements and the candidate's capability.

The requirements are defined by the individual project and its challenges. Use pictures: the project portrait, project challenges, and environmental challenges.

\section{Behavior}

It is a challenge to lead the project team and the individual participants, as the project leader is often a colleague and a peer to them. The role will be accepted as long as

Your authorithy is your own initiative. 


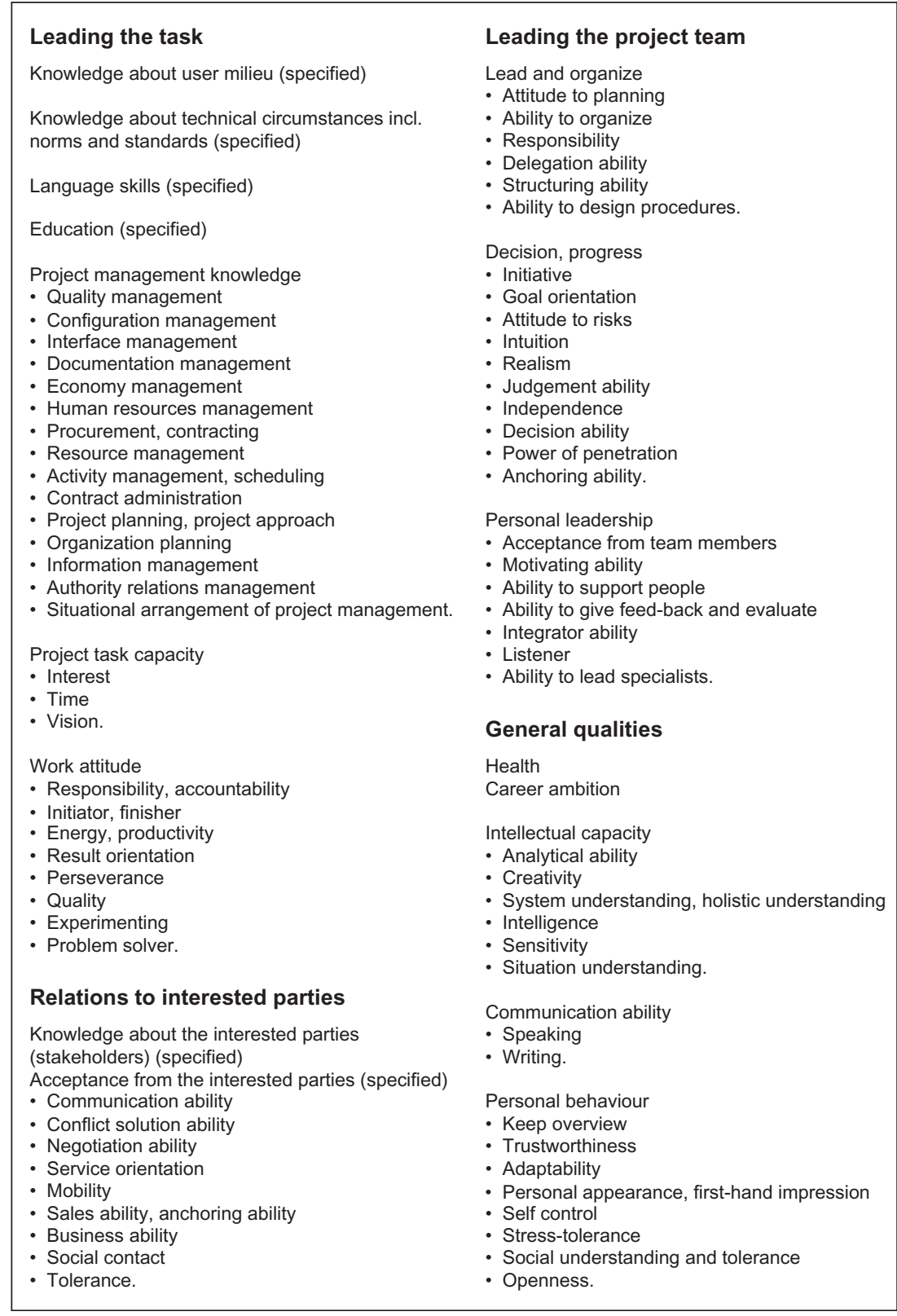

Figure F3. Checklist for Selection of a Project Leader. 


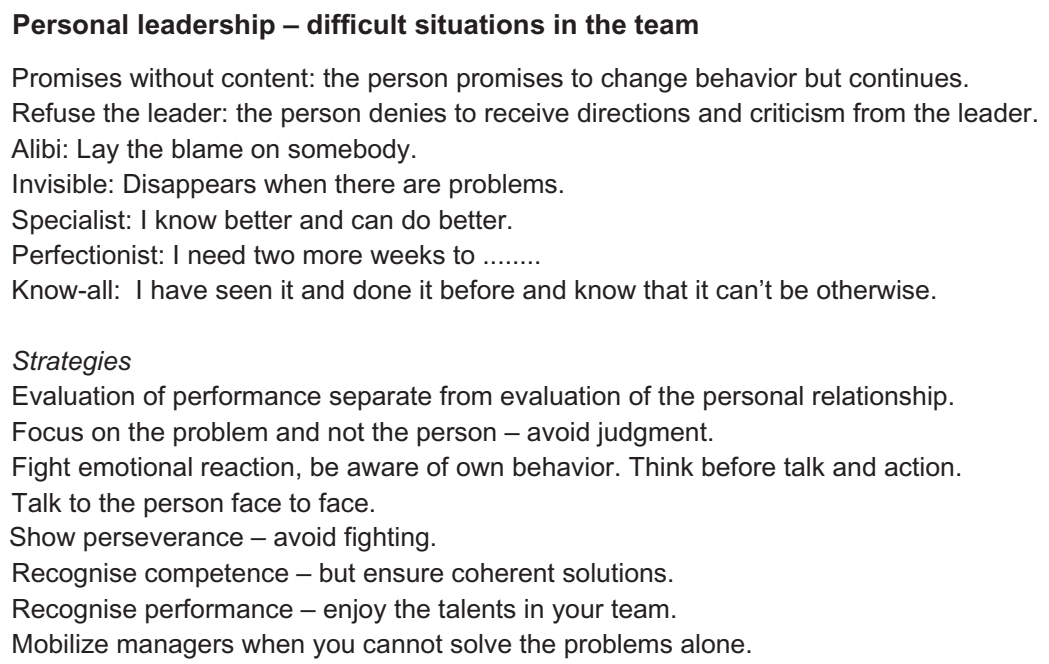

Figure F4. Challenges for Leading the Team.

the leader is perceived as taking care of useful tasks. But tensions may arise, if the project leader feels obliged to exert more personally oriented leadership functions. Figure F4 illustrates some of these tensions.

Another phenomenon is delegation of tasks to participants. The project manager is often recruited with emphasis on the technical content of the project, and may be inclined to do some tasks himself and to supervise the participants. Figure F5 shows some basic principles for delegation.

A third phenomenon is related to the handling of political conditions. Figure F6 offers some advice on such situations, inspired by Morton (1983).

\section{Project Manager's Contract}

Responsibilities and authorities may be defined and described for each of the five elements in the five-by-five model:

- The project task - Scope, goal, selection of solutions, quality level, operations/user economy, implementation 


\section{Good delegation}

Explain the job clearly and thoroughly (problem, expected delivery, criteria for good result,

uncertainties, means, deadline).

Explain background, the whole picture, goal and benefits.

Dialogue about points of attention and questions.

Agree on authority aligned with personal competency and responsibility. "I decide, you deliver proposition". "You decide, but consult me before". "You decide".

Let the person do it his way, but agree on quality assurance.

Do not control all the way.

Agree on checkpoints.

Be accessible for coaching and support.

Express satisfaction with performance and result.

Dialogue about learning.

\section{Your delegation barriers?}

Frequent homework? More workhours than colleagues?

Doing tasks which ought to be done by others?

Do you ask "Who can do this?" when there is a task to be done?

Is your in-basket always filled to the brim when you are absent one day?

Do you not trust your employees? Do you think that some are unmotivated and unwilling?

Do your employees complain that you have no time for dialogue?

Are you doing work not belonging to the project manager job?

Do your employees frequently ask for advice and assistance?

Do you enjoy keeping your eyes skinned?

Do you enjoy knowing everything in your project?

Are you always busy and in a hurry?

Do you have difficulties prioritizing your tasks?

Figure F5. Delegation of Tasks.

- The environment - Analysis and clarification of connections and interfaces

- The resources - Allocation of people and facilities, cost spending, contracts, and agreements

- The interested parties - Contact and communication, commitments, and agreements

- The approach - Work methods and approach, work organization, project control

Conditions and authority should be related to the task. Figure F7 shows a checklist of conditions to be cleared with the project responsible manager/owner. 
Leading a project with strong conflicts between interested parties

Create a positive opinion around the project.

- Ride the project on a wave of interests among the parties. Create the understanding that the project is important and in keeping with actual current.

- Understand the opponents of the project - especially their motives and individual interests. Be aware of parties acting on ideological reasons.

- Focus on the individual interests. Work on them calmly and with consideration. Avoid

- expert pitfall. Experts are often one-sided and there are counter experts. Experts do not convince ideologists.

- law pitfall. Resistance does not disappear by following the rules.

- Sales pitfall. Opponents are not convinced by sales arguments.

- power pitfall. Resistance does not disappear by use of power. Opponents may use irrational methods.

Solve conflicts between parties.

- Develop a strategy for handling the conflicts. Identify the interested parties. Establish negotiations. Build on the influential parties.

- Handle the parties with consideration. Make it a special project for providing the good resources. Arrange anchoring - important parties must take responsibility. Think of the long run - let go of short term gains in favour of long term gains. Be creative and use visible management for creating confidence.

Win team members' heart and interest.

- Use the power of common values. Create solidarity and winning atmosphere.

- Influence and work on the team members. Create understanding of mission and success criterias and the ideas in the approach. Create shared work norms. Help them to succeed and tell them when they do.

Strategies for project management in the political milieu.

- Divide and conquer rule. Allocate tasks to team members. Establish dependencies and cooperation between team members. Establish alliances against threatening parties.

- Take care of shared interests. Offer services and help outside of the project scope.

- Alliance. Create alliance with powerful parties. Link the project to a program or another project.

- Mediate between parties. Tell management that you work based on holistic view and thereby force management to look critically at the partites in the conflict.

- Involve more in sharing responsibility and accountability. Involve important parties in prioritizing problems and in decisions.

- Arrange binding hearings.

- Blame others. Explain using causes you could not control.

- Cooperate. Build the circle of friends. Do them favours expecting to get help in case of problems.

- Obstruct. Delay, postpone, block other projects to get better conditions.

- Sacrifice the future for now. Solve the actual problem without thinking of negative effects later. But be sure to have good explanations when they appear.

Figure F6. Leading in a Political Milieu.

\section{Measuring the Project Manager's Performance}

\section{The project manager's personal performance and his/her results should be evaluated separately, rather than in combination with measuring project results and the project team/organization}


Project manager's contract (referring to project scope)

- Project success criteria

How will they be measured?

- Development perspectives

Image

Spin-off

- Relationship to interested parties

Management attitudes

- Resources

Key persons in the team. Sponsors

Training. Competency development

- Facilities

Equipment, room

- Project Manager's personal development

How should this project contribute?

- Interaction

Interaction with departments

Project responsible manager's role, o.a. outwards

Project manager's responsibility and authority - especially outwards

Interaction between project manager and project responsible manager

- Economy

Budget

Regulation related to uncertainties and opportunities

Figure F7. Project Manager's Contract.

performance. Traditional methods for measuring manager's performance may be applied, adapted to the special circumstances.

Another way of measuring is the competency profile described in tool sheet F.2.

\section{References}

Dobson, M. S. (2001). Project Management for the Technical Professional. Project Management Institute.

Mintzberg, H. (1973). The Nature of Managerial Work. Harper \& Row.

Morton, G. H. A. (1983). Become a Project Champion. International Journal of Project Management 1(4), 197-203. 


\section{F.2. Tool Sheet: Project Leader's Competency}

What

Besides technical qualifications, Your leadership is not determined the project manager's competencies can be divided into three areas. One is the experience acquired from management of by what you know and can, but by how you act, when you don't know what to do.

(Crawford)

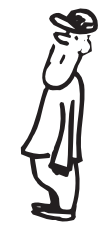
previous projects. Another area is management and control competences - called method competencies - and the third area is behavioral competencies.

Competency includes the use of skills and knowledge and the ability to deliver results. Some project managers have good theoretical knowledge about methods and tools, but are not able to use the methods. At the other end of the spectrum, some project managers exert reasonable management, using methods, but are not able to explain the theoretical background of the methods.

Competency may be based on routine, e.g., that a project manager can lead a certain type of projects and use a set of methods and tools again and again. Competency may also be rooted in a proficiency to find and select methods and tools adapted to a specific project or the actual management situation. Competency is the ability to reflect and learn from leadership situations - being able to lead different types of projects.

Knowledge and skills are connected as illustrated in Kolb's learning cycle. There are four cooperating elements: to decide, to act, to reflect, and to systematize. The first two support the practical experience. The last two represent reflection, acquiring new knowledge and creating new models.

Competency development is often described as a four-phase process. At first, you are unconsciously incompetent; then, you are aware of the need for learning more (consciously incompetent); a training effort makes you consciously competent, but you are not really competent, until you can use what you have learned unconsciously (unconsciously competent). 


\section{Use - Where and When}

The picture of the project manager's competency is used for developing knowledge and skills and for recruiting project managers.

\section{Method}

\section{Experience Competency}

Experience competency is typically described in the personal $\mathrm{CV}-\mathrm{a}$ list of previous projects and assignments. It should contain the following information:

- Projects - what, when

- Project challenges, results, degree of success

- Role in the project

- Lessons learned from each project

\section{Management and Control Competency}

Competency in project management and control disciplines and related methods and tools may be described in a structure based on the five-by-five model. Describe the level of theoretical knowledge and of practical experience. The scale may be: minimal, some, good, satisfying. Evaluation is based on the CV.

The Danish Project Management Association has developed 'competencies in project management' used for certifying project managers. It is also useful for evaluating and planning own competency development. The elements of method competencies are shown in Figure F8. It distinguishes between overall project management and ongoing project management - a distinction not used in this book, because we find it casual and irrelevant. The model focuses on planning project management. It acknowledges differences in the management of different project phases as well. Also the Europe-based association, IPMA has developed a competence baseline, cf. www.ipma.ch.

The US-based association Project Management Institute has a similar model called project management body of knowledge 


\section{Elements of method competencies}

\section{Plan and evaluate project management}

1.1 Characterize project and project management.

1.2 Apply models for project management.

1.3 Plan the specific project management effort.

1.4 Evaluate the performed project management.

1.5 Facilitate the project management processes.

2. Organize the project management phases

2.1 Organize the project preparation phase.

2.2 Organize the project start-up phase.

2.3 Organize the management of project execution.

2.4 Organize the project closing phase.

3. Perform overall project management

3.1 Analyse the project process and environment.

3.2 Handle anchoring with determining parties.

3.3 Develop the project objectives.

3.4 Structure the project task and clarify scope.

3.5 Develop the approach and master schedule.

3.6 Design the project organization structure.

3.7 Provide staffing to the project organization.

3.8 Plan the project economy.

3.9 Perform procurement and enter into contracts.

3.10 Supervise overall plans and manage changes.

\section{Perform on-going project management}

4.1 Plan detailed time schedule and resources.

4.2 Plan the project quality control.

4.3 Monitor the quality, time, resources and costs.

4.4 Establish infrastructure for communication.

4.5 Develop project team co-operation.

4.6 Promote personnel competencies and learning.

4.7 Manage project meetings and correspondence.

4.8 Perform personal leadership and coaching.

4.9 Support handling of project execution tasks.

5. Manage corporate project processes

5.1 Characterise corporate project processes.

5.2 Handle the strategic management processes.

5.3 Handle project-oriented management functions.

5.4 Handle the portfolio management processes.

5.5 Handle program management.

5.6 Develop project management professionalism.

Figure F8. Competencies in Project Management. Source: Competencies in Project Management - National Competence Baseline for Scandinavian, 2008. 
(PMBOK). It has a different structure, but basically the same management functions, including:

1. PM knowledge competencies. The project manager's knowledge about project management, and understanding of project management.

2. PM performance competencies. The project manager's ability to lead a project with success.

3. Personal competencies and behavior.

PMBOK is rather didactic, prescribing certain methods and tools called "best practice." We find this rather doubtful in view of the broad spectrum of projects in society. But the list of management functions is useful. See www.pmi.org.

\section{Behavioral Competency}

Developing managers and leaders, in general, may be supported by many personal development methods. We recommend them for developing project managers as well, because they build on a comprehensive experience basis and well-thought-out methods.

The above-mentioned competencies in project management include a set of leadership behavioral competencies - simple and relevant (see Figure F9). But it seems difficult to define a general behavior profile for project managers due to the variety of projects and project milieus. A differentiated and situationoriented evaluation is necessary - plus inspiration from other characterizations.

The company Bell Labs has conducted a study in search of characteristics of 'star performers' (Kelley \& Caplan, 1993). The result was a set of behavioral elements, such as taking initiative, technical competence, self-management, teamwork effectiveness, networking, leadership, and organizational understanding. The analysis showed that competency lies in the real and active display of behavior, not in the person being conscious about the element, but not showing it. The result of the analysis has inspired us to present a procedure for developing a competency profile, tailored to the 


\section{Competency elements of leadership behavior}

\section{Develop confidence}

6.1 Demonstrate commitment.

6.2 Possess self-control.

6.3 Show reliability.

6.4 Demonstrate openness.

\section{Handle relations}

7.1 Build personal relations.

7.2 Communicate effectively.

7.3 Exercise flexibility.

7.4 Act with assertiveness.

8. Promote dynamics

8.1 Demonstrate group awareness.

8.2 Provide direction.

8.3 Involve participants.

8.4 Stimulate group interaction.

Figure F9. Competency Elements of Leadership Behavior. Source: Competencies in Project Management - National Competence Baseline for Scandinavian, 2008.

individual company - possibly for a specific type of projects (see Figure F10). The advantage is a tailored profile - not a consultant's standard profile. The development process strengthens the participant's understanding of good project management. Figure F11 shows a form for indicating a project manager's competence profile.

\section{Some General Behavioral Models}

The following models for describing behavior may inspire to be used as a tool for evaluating own and other persons' behavior. Each model accentuates certain facets. There is no general model.

Adizes (1985) has defined four roles characterizing good management as a whole:

- The producer $(\mathrm{P})$. The leader must create results. He is the driver and he must know the project, the milieu, and the technology. 


\section{Workshop about 'project manager's competence profile'}

The procedure is:

1. A number of persons from the company/organization are gathered. They should be function and department managers acting as project owners and receivers of project products and results, project managers and project team members.

2. They are introduced to the task - to create a behavioral profile of the good project manager. Plus describe the notion of competence and behavior and how they are visible in action.

3. Each participant should think of one or more project managers who he sees as role model and as a very good project manager. Then think: Why is he/she a good leader? What have I seen her/him doing? Which distinct types of behavior are the reason for good results and for recognition as a good leader?

4. Each participant chooses the five most important behavioral elements and write them on a card (one per card and described by three to five words) and prioritize them.

5. The workshop leader asks for the most important element from one participant and puts it on the wall. The participant describes and gives reasons for the element. Then the participants choose from their cards elements, which are the same or a similar meaning. They are placed below the first card. Allow a discussion of the meaning and maybe different wording. Find a headline for the column.

6. Then, the workshop leader asks another participant for an important element, puts it on the wall, and the above process is repeated.

7. Continue until all cards are on the wall. The result will be 10-15 elements (columns) - some with agreement from many participants and some with few defenders. Then prioritize in common and cut down to seven to ten elements.

8. These elements are described by a headline and a short sentence, based on the cards in the column and the discussion. They are turned into an evaluation model with a scale. Illustration A5.2-05 shows some examples of typical elements from similar workshops.

9. The evaluation form is then used by project managers - primarily at the regular evaluation interview, but also as feedback from project team members and interested parties (stakeholders).

Figure F10. Workshop about Project Manager's Competency Profile.

- The administrator (A). The leader must guide his organization to deliver results. He must plan, coordinate, formulate norms and rules, create procedures, and monitor.

- The entrepreneur (E). The leader must be capable of independent action, able to see possibilities for action, plan and act, and live with uncertainty and risk.

- The integrator (I). The leader must organize the team and motivate the members and create cooperation.

Adizes calls it unsatisfactory management, if the project manager masters none or only one of these abilities. The 


\section{Project managers' competence profile}

Project manager's visible behaviour is described by the elements below. For each element, the level is indicated on this scale:
1. Minimal use
2. Some use
3. Good use
4. Quite satisfactory use.

The profile is described by the project manager and his personal leader, or with his core team members.

Name: $\quad$ Date:

\begin{tabular}{|c|c|c|c|c|}
\hline \multirow[t]{2}{*}{ Competenc } & \multicolumn{4}{|c|}{ Visible use } \\
\hline & 2 & 3 & 4 & Examples \\
\hline \multicolumn{5}{|c|}{$\begin{array}{l}\text { Organizes the work. } \\
\text { Delegates tasks and responsibility } \\
\text { Coordinates cooperation between } \\
\text { participants. Prioritizes tasks }\end{array}$} \\
\hline \multicolumn{5}{|c|}{$\begin{array}{l}\text { Listens and talks. } \\
\text { Is open-minded, curious and good } \\
\text { listener. Encourages and supports. } \\
\text { Evaluates }\end{array}$} \\
\hline \multicolumn{5}{|c|}{$\begin{array}{l}\text { Acts in a competent way. } \\
\text { Takes responsibility and solves the } \\
\text { problems. Knows the judgment } \\
\text { and acts proactively }\end{array}$} \\
\hline \multicolumn{5}{|c|}{ Has overview. } \\
\hline \multicolumn{5}{|c|}{ Creates cooperation. } \\
\hline \multicolumn{5}{|l|}{ Is energetic. } \\
\hline \multicolumn{5}{|l|}{ Is honest. } \\
\hline \multicolumn{5}{|c|}{ Creates engagement. } \\
\hline \multicolumn{5}{|c|}{ Supports and cooperates. } \\
\hline \multicolumn{5}{|l|}{ Informs. } \\
\hline Is captain. & & & & \\
\hline
\end{tabular}

These are but some examples from companies

Figure F11. Example of a Competency Profile Form.

manager should master all four roles, although not necessarily perfectly. It will often be better to compose a leader team with persons supplementing each other, e.g., PaeI + pAeI + paEI, (the size of the letters indicates the degree of 
mastering). Adizes has the following model for a group leading a project:

- paeI, the integrator creating cooperation.

- PaEi, the member ensuring results on time and implemented.

- pAEi, the administrator handling practical administrative elements.

- paEI, the reviewer and process observer.

- pAEi, the reporter outwards and upwards.

- paEi, resource persons in the group.

A simple model is to distinguish between democratic and authoritarian management. It describes how the manager involves team members in decisions. The following scale is used:

- Hard-boiled authoritarian

- Attentive authoritarian (patriarchal)

- Laissez-faire

- Consulting democratic

- Involving democratic

Behavior also includes the way he relates to other people. Examples include:

- Reserved versus open

- Warm versus hard

- Formal versus informal

- Proactive versus hesitant

- Sure versus searching

The Myers-Briggs type indicators (2014) describe four dimensions of the attitude to tasks. The first dimension describes the 
general attitude. The extrovert person gets energy from the environment, whereas the introvert gets energy from the inner (own) world. The second dimension describes the way of understanding and perceiving the situation - either by sensing via working with known facts, or by intuitively looking for opportunities and connections. The third dimension describes how the person evaluates propositions and solutions - either based on objective analysis and logic, or based on personal values. The fourth dimension is a general way of life - either a planned, arranged lifestyle, or a flexible, spontaneous lifestyle.

Blake and Mouton (1962) created 'the managerial grid' characterizing leaders by the degree of production (performance) orientation and the degree of people orientation. It is a matrix with different styles - see Figure F12. The following four styles are of special interest:

- (1.1) The leader shows minimal initiative in all areas. Does not take on more responsibility than prescribed. Passes on orders

The managerial grid

Care for people

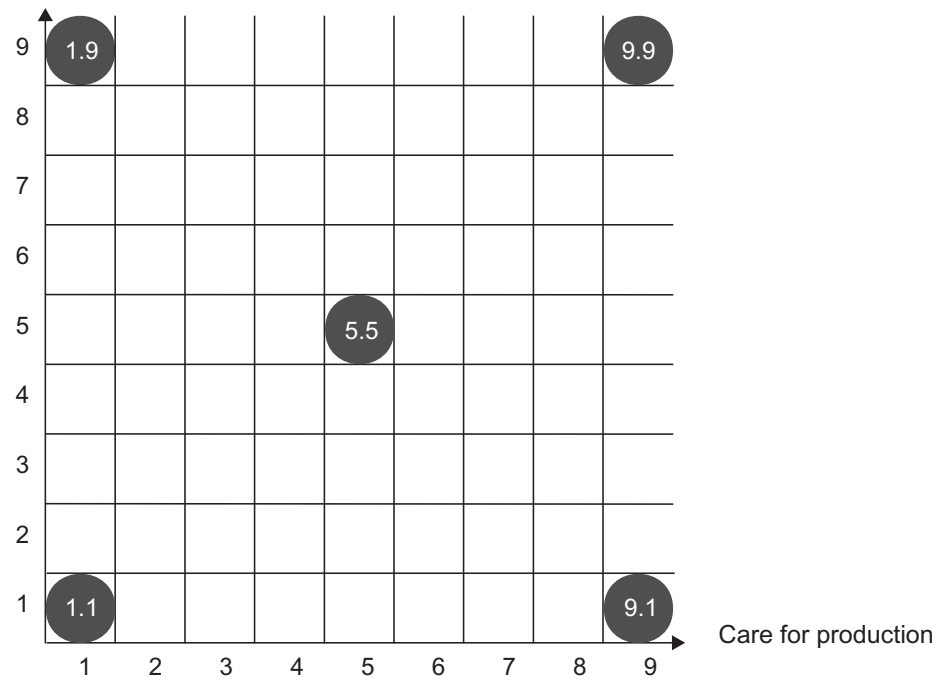

Figure F12. The Managerial Grid. 
from superior managers without taking a stand - acts as a messenger. Arguments for decisions are prescribed rules, precedence or orders from superior managers. The leader is rather passive and participates only in meetings as required. The primary effort aims to stay in the organization.

- (1.9) The leader cares about her/his employees. Focus is on well-being and good working climate, and social life in the team. She/he does not push for results, because she/he thinks this conflicts with good working climate. She/he is hearty and pleasant and avoids conflicts and decisions involving tensions.

- (9.1) The leader focuses on maximum production results. She/he requires full work effort, and has little confidence in employees' feeling of responsibility and interest in doing their best. She/he exerts tight control and suppresses their independent decisions and personal needs, because she/he thinks that this conflicts with maximum production result. Planning is separated from doing, and effort is controlled by positive and negative sanctions.

- (5.5) The leader is compromising - trying to be fair. She/he reduces requirements to production, because she/he wants to consider personal needs and vice versa. She/he thinks that there are always conflicting interests - it is necessary to meet midway.

These four styles build on the assumption that consideration of people conflicts with consideration of production. The difference is in the prevailing orientation.

- (9.9) The optimizing leader sees it otherwise. Her/his behavior builds on the assumption that there is no conflict between consideration of production and consideration of people. Under the right circumstances, people will feel responsibility and be engaged in their work. They will develop independence and creativity and feel pleasure and personal satisfaction through results. The leader counteracts alienation from work by not separating planning and doing. Planning is done by the persons 
doing the work - in teamwork. The culture is characterized by personal engagement. Communication is open and direct. Conflicts are not suppressed, but discussed. 4Human needs and feelings are seen as drivers in the project.

The managerial grid assumes an ideal and best behavior. Other authors believe that behavior should be adapted to the individual situation. Hersey, Blanchard, and Johnson (2013) present a model called situational leadership, in which the leader's behavior is described in two dimensions. One is task-oriented behavior indicating to which degree the leader explains the team/team member what to do, when, where, and how. The other dimension is social-oriented behavior. It indicates to which degree the leader is in dialog with the team/team member and offers consultative support, encourages, and facilitates. The behavior should also be adapted to the work maturity of the team/team member.

\section{Match Between Project Manager's Competency and Style and the Type of Project}

Studies of project management indicate that the managerial style influences the project's success, and that the type of project and the individual project phases require certain competencies. A general factor guiding the style is whether the project is a delivery project with a well-defined goal and plan, or a change project where the user's situation, performance and understanding will change.

In the following, we describe a competency model for project managers, developed by Dulewicz and Higgs (2003). The model has 15 competencies connected to successful project management. The competencies are developed from studies of behavioral models, published and used in the last 80 years. The relevance for project managers is confirmed through several analyses, done by Dulewicz and Higgs and by other researchers. Some of these analyses (among others Müller \& Turner, 2010) relate the importance of the competence elements to project complexity, degree of change, strategic importance, technological type, and type of 


\begin{tabular}{|c|c|}
\hline Competence & Importance \\
\hline \multicolumn{2}{|l|}{ Emotional competencies } \\
\hline $\begin{array}{l}\text { Motivation - has drive and energy to reach clear results } \\
\text { and effects. }\end{array}$ & Important for all types. \\
\hline $\begin{array}{l}\text { Conscientiousness - demonstrates clear commitment to } \\
\text { goal and plan, when there are challenges. Encourages } \\
\text { other people to assist. 'Walks the talk'. }\end{array}$ & Important for all types. \\
\hline $\begin{array}{l}\text { Interpersonal sensitivity - is observant and considers } \\
\text { other peoples' needs and opinion. }\end{array}$ & Important for all types. \\
\hline $\begin{array}{l}\text { Influences - can influence other people to change } \\
\text { opinion - understanding their position and argumenta- } \\
\text { tion. }\end{array}$ & Important for all types. \\
\hline $\begin{array}{l}\text { Self-awareness - is aware of own feelings and can control } \\
\text { them. }\end{array}$ & $\begin{array}{l}\text { Medium importance for engineering } \\
\text { projects and improvement projects. }\end{array}$ \\
\hline $\begin{array}{l}\text { Emotional resilience - can deliver results in different } \\
\text { situations. Keeps focus on plan and result in spite of } \\
\text { personal challenges and critics. }\end{array}$ & $\begin{array}{l}\text { Medium importance for improvement } \\
\text { projects. Little importance for } \\
\text { engineering projects. }\end{array}$ \\
\hline $\begin{array}{l}\text { Intuitiveness - makes clear decisions and carries out, in } \\
\text { spite of incomplete and uncertain information. Builds on } \\
\text { rationality and feeling as well. }\end{array}$ & $\begin{array}{l}\text { Little importance for engineering } \\
\text { projects. Medium importance for other } \\
\text { types excl. strategic repositioning. }\end{array}$ \\
\hline \multicolumn{2}{|l|}{ Leadership competencies } \\
\hline $\begin{array}{l}\text { Managing resources - organizes resources and coordi- } \\
\text { nates effectively. Formulates goals and action plans. }\end{array}$ & $\begin{array}{l}\text { Medium importance for engineering } \\
\text { projects. }\end{array}$ \\
\hline $\begin{array}{l}\text { Engaging communication - engages other people and } \\
\text { gains their support through communication, adapted to } \\
\text { each part. Is sociable and accessible. }\end{array}$ & $\begin{array}{l}\text { Medium importance for engineering } \\
\text { projects and simple improvement } \\
\text { projects. }\end{array}$ \\
\hline $\begin{array}{l}\text { Developing - encourages people to take on challenging } \\
\text { tasks and responsibility. Developing peoples' competen- } \\
\text { cies and coaches. }\end{array}$ & $\begin{array}{l}\text { Medium importance for organization } \\
\text { development projects. }\end{array}$ \\
\hline $\begin{array}{l}\text { Empowering - gives people independence and encour- } \\
\text { ages to take on challenging tasks. }\end{array}$ & $\begin{array}{l}\text { Little importance for engineering } \\
\text { projects. }\end{array}$ \\
\hline $\begin{array}{l}\text { Achieving - shows firmness in reaching goals, carrying } \\
\text { out decisions and delivering results. }\end{array}$ & $\begin{array}{l}\text { Important for IT projects and develop- } \\
\text { ment projects. Otherwise medium } \\
\text { importance. }\end{array}$ \\
\hline \multicolumn{2}{|l|}{ Intellectual competencies } \\
\hline $\begin{array}{l}\text { Strategic perspective - is aware of broader connections } \\
\text { and problems. Balances short term and long term } \\
\text { considerations and sees opportunities and risks. }\end{array}$ & $\begin{array}{l}\text { Medium importance for engineering } \\
\text { projects and improvement projects. }\end{array}$ \\
\hline $\begin{array}{l}\text { Vision and imagination - inventive and innovative. Has a } \\
\text { clear vision and sees how changes influence implementa- } \\
\text { tion and business. }\end{array}$ & $\begin{array}{l}\text { Little importance for engineering } \\
\text { projects. Medium importance for } \\
\text { improvement projects. }\end{array}$ \\
\hline $\begin{array}{l}\text { Critical analysis and judgment - gathers relevant } \\
\text { information from more sources. Tests information and } \\
\text { evaluates advantages and disadvantages. Good decisions } \\
\text { considering effect and potential critical conditions. }\end{array}$ & Important for all types. \\
\hline
\end{tabular}

\section{Figure F13. Dulewitz and Higgs Company Model.}


contract. The elements are listed in Figure F13, with comments on their importance for different types of projects (based on Müller \& Turner).

You can remove the descriptions of importance and use the form as a tool for evaluation and prioritization of competencies in individual projects. We recommend a situational prioritization of the importance, based on project type, complexity, and type of contract.

\section{References}

Adizes, I. (1985). How to Solve the Mismanagement Crisis. Adizes Institute.

Blake, R. R., \& Mouton, J. (1962). The Managerial Grid. Scientific Methods, Austin, Texas.

Competencies in Project Management - National Competence Baseline for Scandinavian (2008). Version 3.0. The Danish Project Management Association.

Dulewicz, V., \& Higgs, M. J. (2003). Design of a new instrument to assess leadership dimensions and styles. Henley Management College.

Hersey, P., Blanchard, K. H. \& Johnson, D. H. (2013). Management of organizational behavior: Leading human resources (10th Ed.). Pearson.

Kelley, R., \& Caplan, J. (1993). How Bell Labs creates star performers. Harvard Business Review, July-August, 128-139.

Kolb, D. (1984). Experimental Learning. Englewood Cliffs: Prentice Hall.

MBTI Basics (2014). Myers \& Briggs Foundation. Retrieved from http://www.myersbriggs.org

Müller, R., \& Turner, R. (2010). Leadership competency profiles of successful project managers. International Journal of Project Management, 28(5). 


\section{F.3. Tool Sheet: Project Leader's Plan}

What

The leader's plan deals with elements that require managerial effort as well as related methods. It is not necessar-

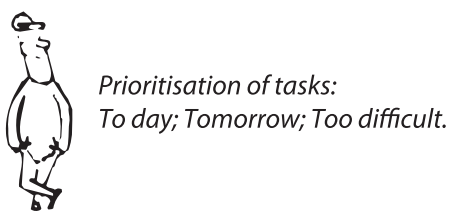
ily a written plan, but a way of consciously work with the management task.

\section{Use - Where and When}

The plan is relevant throughout the project.

To delegate is to dare the risk, that somebody else can do it better than you

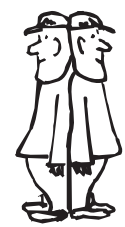

\section{Method}

The leader's plan encompasses the project manager's activities in the project plan, and the manager's general management and control actions. It includes the handling of issues and points of special attention. They are related to the milestones, and are therefore important for the manager. Figure F14 shows typical elements of the plan.

The project manager should decide his/her style, how to handle conflicts, the decision process etc. We recommend a planning rhythm - time reserved weekly for reflection and planning:

- New points of attention.

- Points of attention in the coming two weeks.

- Walk through the activity plan for the next two to three weeks. Note preparations necessary for 'healthy' activities in these weeks.

- Personal action plan for next week.

A broad set of tools and methods is necessary in a large project. The leader will use a smaller set in a smaller project - some of them are quite simple tools. A guide to selecting tools is difficult to 


\section{Management plan}

- Think of the work ahead of you and your team in the near future, and analyze. List areas/points of special attention.

- List tasks/subjects/issues which need special leadership attention and effort. Describe the problem/case.

- Plan strategy in the approach.

Goal, approach, conflict handling, decision process.

Who should do what?

- Plan own (personal) activity and leadership style.

Own role - active work, influnce on team members, influence on interested parties.

Own style and behavior.

Own effort and action.

\section{Figure F14. Project Leader's Plan.}

\begin{tabular}{|c|c|}
\hline \multicolumn{2}{|c|}{ A strategy for leading a medium-size product or systems development project } \\
\hline Phase plan & $\begin{array}{l}\text { Use a phased approach with step-wise building of solutions. } \\
\text { Avoid acceptance crisis at the end. }\end{array}$ \\
\hline Project start & Make a qualified effort for the correct project scope and main objectives. \\
\hline Interfaces & $\begin{array}{l}\text { Focus on interfaces - especially the human and organizational. } \\
\text { They are the typical origin of problems. }\end{array}$ \\
\hline Communication & $\begin{array}{l}\text { Involve persons, provide information. High level of } \\
\text { information ensures correct actions and ensures acceptance. }\end{array}$ \\
\hline $\begin{array}{l}\text { Communication } \\
\text { coordinator }\end{array}$ & $\begin{array}{l}\text { Appoint possibly a project team member as responsible for practical } \\
\text { administration of documentation. }\end{array}$ \\
\hline Influence & $\begin{array}{l}\text { Involve affacted people in planning, development and decision processes } \\
\text { to ensure quality and acceptance. }\end{array}$ \\
\hline Resources & $\begin{array}{l}\text { Allocate qualified team members - they are the key to qualified results. } \\
\text { Follow up on part-time members especially. They may delay the work. }\end{array}$ \\
\hline Work room & $\begin{array}{l}\text { Arrange a project team room with place for team members and for meetings. } \\
\text { Hang plans and other important information on the wall. }\end{array}$ \\
\hline Control & $\begin{array}{l}\text { Use simple planning tools - Gantt-chart and milestone plan. Plan together in } \\
\text { the team. Act in the actual situation - list issues and areas of attention. } \\
\text { Follow up on plans and agreements. Use status report and progress curve. }\end{array}$ \\
\hline Work pattern & $\begin{array}{l}\text { Use short steering meetings and workshops and seminars. Adapt the } \\
\text { work pattern to the actual situation. }\end{array}$ \\
\hline
\end{tabular}

Figure F15. Management of a Small Project.

present, but Figure F15 may be of help. Figure F16 shows key elements of a plan for own work. It is important to update the plan every day. Figure F17 shows a form for a personal weekly plan. 


\section{Plan your own work!}

Tools

- Task list for each job - each project and other jobs as well. List agreed tasks and planned tasks.

- Calendar. Show agreements and reserved time periods - o.a. meetings.

- Day or week plan. Show planned and agreed tasks per day/week and their order of execution.

- To-do list. Show all small tasks to be done in between - e.g. telephone calls, letters. Note also new things to be done and remembered.

\section{Planning}

- Every day, the to-do list is cleared, and remaining tasks are transferred to next day's to-do list or to the day/week plan.

- Every week, a new week plan is arranged using the registered tasks to be done. Estimate time consumption and capacity. Remember to reserve capacity for upcoming new tasks. Use your experience.

- Arrange as far as possible to finish each task without interruptions.

- Set out time for new tasks and meetings before you make agreements - to ensure best arrangement for you (proactive planning).

- Note expected, but not yet agreed tasks.

- Learn to say no to tasks. Use your plan as an argument.

Follow up

- Cross out tasks done.

- Register your time spent, to gain experience with time consumption and capacity.

- Use the amount of delayed tasks as indicator of unrealistic planning.

Figure F16. Plan for Own Work.

\section{Week Plan}

\section{Activities to-do per week. May contain all personal activities in more projects and in other assignments.}

\section{Work Plan}

Activities related to this project.

\section{Project Logbook}

Chronological diary for the project. 


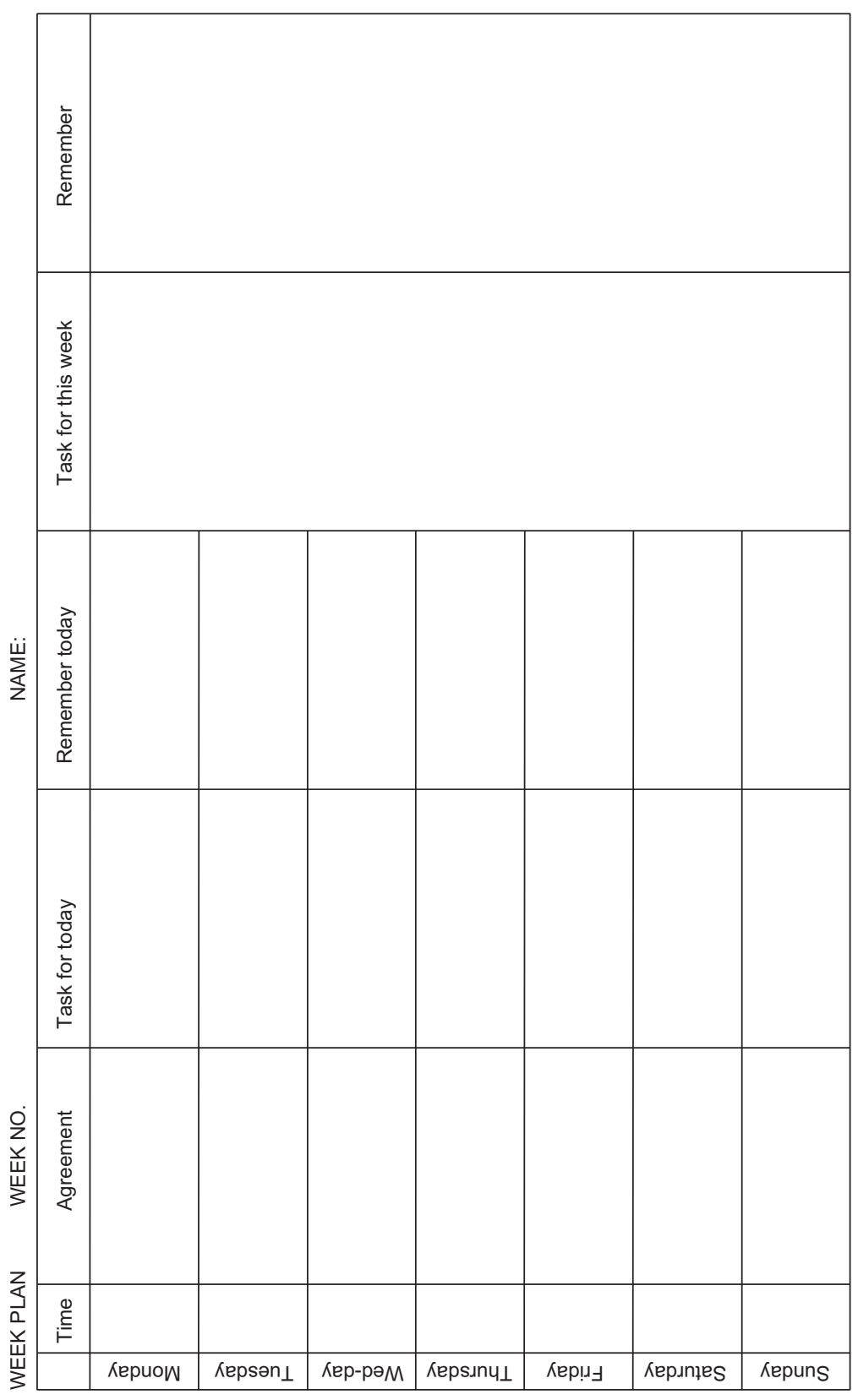

Figure F17. Week Plan. 